\title{
A novel method for preparing highly porous gadolinia-doped-ceria ceramics
}

\author{
Feng-Yun Wang a,b,*, Soofin Cheng ${ }^{\mathrm{a}, * *}$, Ben-Zu Wan ${ }^{\mathrm{c}}$, \\ Chen-Hung Chung ${ }^{\text {a }}$, Mei-Ju Chen ${ }^{\text {a }}$ \\ ${ }^{a}$ Department of Chemistry, National Taiwan University, Taipei 106, Taiwan \\ ${ }^{\mathrm{b}}$ School of Chemistry, Huazhong Normal University, Wuhan, Hubei 430079, PR China \\ ${ }^{\mathrm{c}}$ Department of Chemical Engineering, National Taiwan University, Taipei 106,Taiwan \\ Received 6 February 2007; received in revised form 5 June 2007; accepted 20 July 2007 \\ Available online 19 August 2007
}

\begin{abstract}
Highly porous $\mathrm{Ce}_{0.8} \mathrm{Gd}_{0.2} \mathrm{O}_{1.9}$ (CGO) was prepared with a novel method by acid leaching MgO from MgO-CGO ceramics (CGM) with acetic acid solution. Effects of leaching conditions and $\mathrm{MgO}$ content in CGM were studied. Under proper conditions (60 vol\% acetic acid solution, $358 \mathrm{~K}$, $8.5 \mathrm{~h}$ ), $\mathrm{MgO}$ in CGM ceramics can be effectively leached out, but no CGO can be dissolved. The porosity of the sufficiently leached pellet increases with the increasing $\mathrm{MgO}$ content, but too much $\mathrm{MgO}$ can result in the collapse of the leached pellet. The suitable value of $\mathrm{MgO} / \mathrm{CGO}$ is about 3.3. With the novel method, a highly porous CGO pellet was prepared with a porosity of $68 \%$ which is much higher than that $(\sim 50 \%)$ with graphite as pore former.
\end{abstract}

(C) 2007 Elsevier Ltd and Techna Group S.r.l. All rights reserved.

Keywords: B. Porosity; D. MgO; E. Electrodes; E. Fuel cells

\section{Introduction}

Porous ceramics have many applications, such as fuel-cell electrodes [1]. In the works [2,3] developing copper-based, ceramic-metallic (cermet) composites for direct oxidation of hydrocarbon fuels in intermediate temperature solid oxide fuel cells (ITSOFCs) with $\mathrm{Ce}_{0.8} \mathrm{Sm}_{0.2} \mathrm{O}_{1.9}$ (CSO) as electrolyte, the synthesis of a porous CSO matrix is the first step in fabrication. Unlike traditional Ni-CSO cermets, which can be formed simply by cosintering $\mathrm{NiO}$ and $\mathrm{CSO}$ powders and subsequently reducing $\mathrm{NiO}$ to nickel, it is difficult cosintering mixtures of copper oxides and $\mathrm{CSO}$ powders because $\mathrm{Cu}_{2} \mathrm{O}$ and $\mathrm{CuO}$ melt at temperatures below those necessary for CSO sintering. To avoid this problem, Gorte and co-workers [2,3] prepared $\mathrm{Cu}-$ $\mathrm{CeO}_{2}-\mathrm{CSO}$ cermets by impregnating soluble salts of copper and cerium into a porous CSO structure after the CSO

\footnotetext{
* Corresponding author at: School of Chemistry, Huazhong Normal University, Wuhan, Hubei 430079, PR China. Tel.: +86 2767867953.

** Corresponding author. Tel.: +886 2 33661662; fax: +886 223636359 .

E-mail addresses: sxwfy@hotmail.com (F.-Y. Wang),

chem1031@ntu.edu.tw (S. Cheng).
}

electrolyte layer had been sintered. Because the cermet anode should be $\sim 50 \%$ metal to ensure electronic conductivity and should still remain highly porous to allow diffusion of fuel to the electrolyte interface, high initial porosity is desirable for the porous CSO before the addition of copper oxides.

There are several standard methods for preparing porous ceramics. Most commonly, the porous structures are produced by sintering powders made up of different particle sizes [4]. In this case, a porous network is formed by the spaces between the necked powders, and it is difficult to achieve porosities greater than $\sim 45 \%$. Higher porosities can be achieved through the use of pore formers $[5,6]$. Here, sacrificial compounds, such as graphite or starch, are added to the green body and are removed during calcination, leaving behind a porous ceramic. Using graphite as pore former, Gorte and co-workers [2,3] have prepared a porous CSO ceramic at $1773 \mathrm{~K}$ for copper-based anode, and found that the porosity could only achieve $\sim 50 \%$. In addition, Gorte and co-workers [7] have created another method to prepare porous yttria-stabilized zirconia (YSZ) by using $\mathrm{NiO}$ as pore former. This method involves cosintering $\mathrm{NiO}-\mathrm{YSZ}$ green tape at $1800 \mathrm{~K}$, reducing with $\mathrm{H}_{2}$ at $973 \mathrm{~K}$ for $10 \mathrm{~h}$, and leaching $\mathrm{Ni}$ from the formed Ni-YSZ cermet with 
$2.2 \mathrm{M} \mathrm{HNO}_{3}$ at $353 \mathrm{~K}$. Using this method, the porous $\mathrm{YSZ}$ achieved a porosity of $55-70 \%$. However, this method cannot be applied to the preparation of porous CSO and other doped ceria because, in the acid leaching step, the hot and strong nitric acid can result in considerable dissolving of doped ceria, and that the hydrogen reducing step can cause partial reduction of the doped ceria electrolyte layer, which in turn causes lower open circuit voltage and lower power output of the fuel cells.

Similar to CSO, $\mathrm{Ce}_{0.8} \mathrm{Gd}_{0.2} \mathrm{O}_{1.9}$ (CGO) has been widely studied as ITSOFC electrolyte and found even better than CSO in ionic conductivity [8-10]. In order to develop highly porous anode for direct hydrocarbon ITSOFCs with CGO as electrolyte, it is necessary to develop an effective way to prepare highly porous CGO ceramics.

In this work, we developed a novel method to prepare highly porous $\mathrm{CGO}$ by acid leaching $\mathrm{MgO}$ directly from $\mathrm{MgO}-\mathrm{CGO}$ ceramics with acetic acid solution. The effects of $\mathrm{MgO}$ content and acid leaching conditions were studied. Using this method, highly porous CGO ceramics with porosity of $68 \%$ were prepared.

\section{Experimental}

\subsection{CGO powder preparation}

The starting materials were the nitrate salts of reagent grade (Acros) and used as purchased. An aqueous solution of $\mathrm{Ce}^{3+}$ and $\mathrm{Gd}^{3+}$ with $\mathrm{Ce} / \mathrm{Gd}=4$ was prepared in a beaker. Then, citric acid (CA) and polyethylene glycol (PEG) with the weight ratio of $\mathrm{CA} / \mathrm{PEG}=60$ were added until the molar number of citric acid was equal to the total number of the metal ions in the beaker. The mixed solution was evaporated under stirring at $353 \mathrm{~K}$ until the solution gelled. The gel was dried at $378 \mathrm{~K}$, ground and calcined in air at $973 \mathrm{~K}$ for $4 \mathrm{~h}$, and then ground again to form CGO powder.

\subsection{Porous $C G O$ pellet preparation}

$\mathrm{MgO}$ powder was prepared by calcining $\mathrm{Mg}\left(\mathrm{NO}_{3}\right)_{2} \cdot 6 \mathrm{H}_{2} \mathrm{O}$ (Acros) at $773 \mathrm{~K}$ for $4 \mathrm{~h}$, and mixed with the CGO powder in a molar ratio of $x=\mathrm{MgO} / \mathrm{CGO}=1.0-3.3$. The mixture was ball milled into fine powder and pressed uniaxially into green pellets with a stainless steel die (diameter: $13.05 \mathrm{~mm}$ ) under $750 \mathrm{MPa}$. The green pellets were sintered in air at $1773 \mathrm{~K}$ for $5 \mathrm{~h}$ into dense pellets [termed as $\mathrm{CGM}_{x}(\mathrm{~S})$ ], leached with acetic acid solution $(60 \mathrm{vol} \%)$ at about $358 \mathrm{~K}$ for a sufficient time $(>8 \mathrm{~h})$, rinsed with distilled water to remove $\mathrm{Mg}^{2+}$, and finally dried at $473 \mathrm{~K}$ over night. The leached pellets were termed as $\mathrm{CGM}_{x}(\mathrm{~L})$. The leaching-out rate of $\mathrm{MgO}$ (termed as $\mathrm{LRMg}$ ) was calculated by the weight difference of the pellet before and after the leaching.

\subsection{Sample characterization}

The diameter and thickness of all the pellet samples were measured with vernier caliper and micrometer for the calculation of pellet volumes and linear shrinkages with

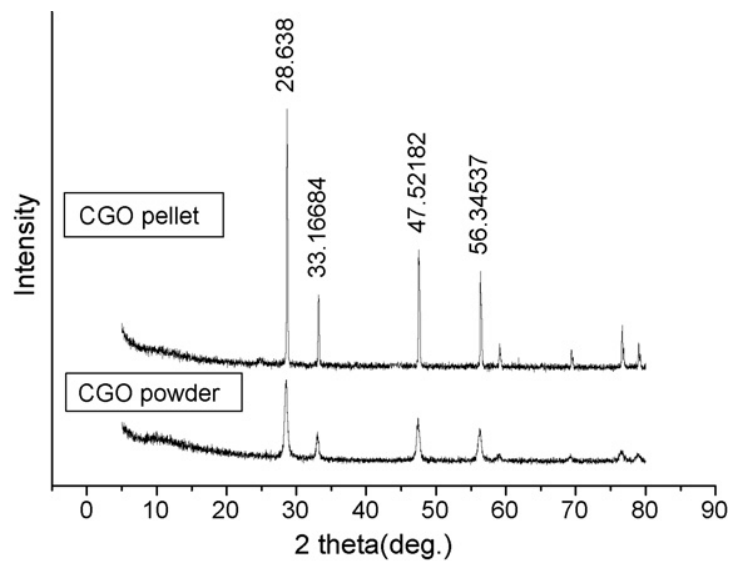

Fig. 1. XRD patterns of CGO powders (calcined at $973 \mathrm{~K}$ for $4 \mathrm{~h}$ ) and pellet (sintered at $1773 \mathrm{~K}$ for $5 \mathrm{~h}$ ).

respect to the green pellets. The linear shrinkages of sintered and leached pellets were calculated only with the diameter data. The porosities of the pellet samples were measured by mercury porosimetry (Pore Master 33). The compositions of pellet samples and filtrate from the acid leaching process were analyzed by inductively coupled plasma-atomic emission spectrometer (ICP-AES) (Jarrell-Ash, ICAP9000). Before the analysis, pellet samples need to be dissolved hydrothermally in a $\mathrm{HF}$ and $\mathrm{HNO}_{3}$ solution at $453 \mathrm{~K}$ for $15 \mathrm{~h}$. The crystal structures of the samples were identified at room temperature using a PANalytical X-ray diffractometer $(\mathrm{Cu} \mathrm{K} \alpha$ radiation). Scanning electron microscopy (SEM) analysis of the crosssection of pellet samples was conducted on a Hitachi S-2400 electron microscope. The relative density of the dense CGO pellet was measured by Archimedes' method. The ionic conductivity of the dense CGO pellet was measured in air with $\mathrm{AC}$ impedance equipment (Autolab).

\section{Results and discussion}

Fig. 1 shows the XRD patterns of the synthesized CGO powder and the dense pellet which was prepared with the

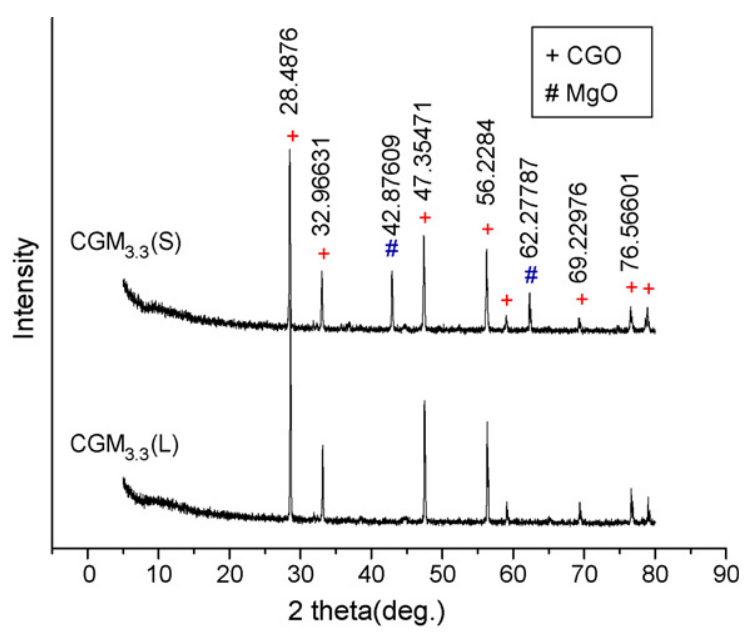

Fig. 2. XRD patterns of $\mathrm{CGM}_{3.3}(\mathrm{~S})$ and $\mathrm{CGM}_{3.3}(\mathrm{~L})$. 


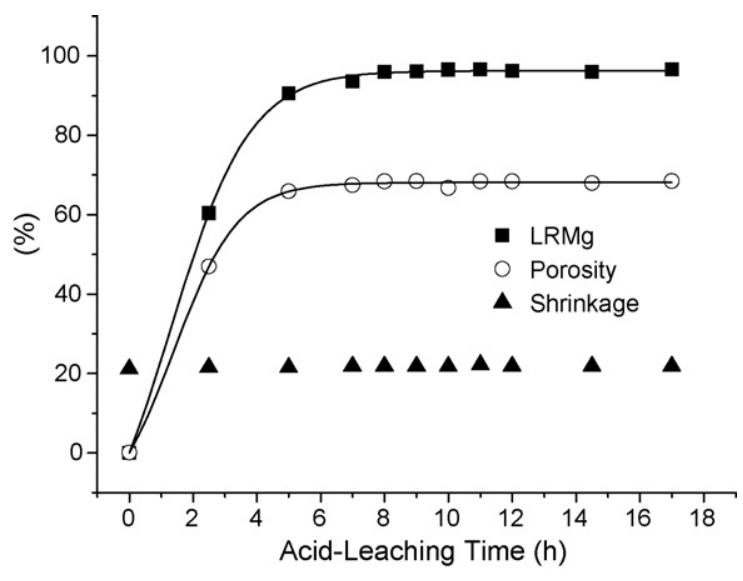

Fig. 3. Effect of acid leaching time on LRMg, porosity, and shrinkage of $\mathrm{CGM}_{3.3}(\mathrm{~S})$ pellet (pellet $0.4 \mathrm{~g} ; 60 \mathrm{vol} \%$ acetic acid $25 \mathrm{ml} ; 358 \mathrm{~K}$ ).

powder by pressing under $750 \mathrm{MPa}$ and sintering at $1773 \mathrm{~K}$ for $5 \mathrm{~h}$. The powder and the pellet had the same XRD patterns as that of standard pure ceria except that the pellet had sharper peaks (due to higher sintering temperature and better crystallization) than the powder. These results suggest that both the powder and the pellet are single phase of ceria-based solid solution. The relative density (91\%) and ionic conductivity (at $973 \mathrm{~K}, 0.0321 \mathrm{~S} \mathrm{~cm}^{-1}$ ) of the dense CGO pellet indicate that the CGO powder is suitable for preparing dense electrolyte and porous anode, and that the sintering conditions are acceptable.

Fig. 2 shows the XRD patterns of the $\mathrm{CGM}_{3.3}(\mathrm{~S})$ and $\mathrm{CGM}_{3.3}(\mathrm{~L}) . \mathrm{CGM}_{3.3}(\mathrm{~S})$ was observed two phases, $\mathrm{MgO}$ and $\mathrm{CGO}$. Since $\mathrm{MgO}$ had been reported to have a solubility of $2 \%$ in $\mathrm{CeO}_{2}$ at $1873 \mathrm{~K}$ [11], little $\mathrm{MgO}$ might also be dissolved here into the CGO lattice. After sufficient acid leaching, the sample $\mathrm{CGM}_{3.3}(\mathrm{~L})$ was observed only in one phase of CGO. Composition analysis by ICP revealed that the remnant $\mathrm{MgO}$ in $\mathrm{CGM}_{3.3}(\mathrm{~L})$ was less than 4 wt.\%, and that no $\mathrm{Ce}^{3+}, \mathrm{Ce}^{4+}$, and $\mathrm{Gd}^{3+}$ were detected in the filtrate from acid leaching process. These results suggest that $\mathrm{MgO}$ in $\mathrm{CGM}_{3.3}(\mathrm{~S})$ can be effectively leached out, but no CGO can be dissolved.

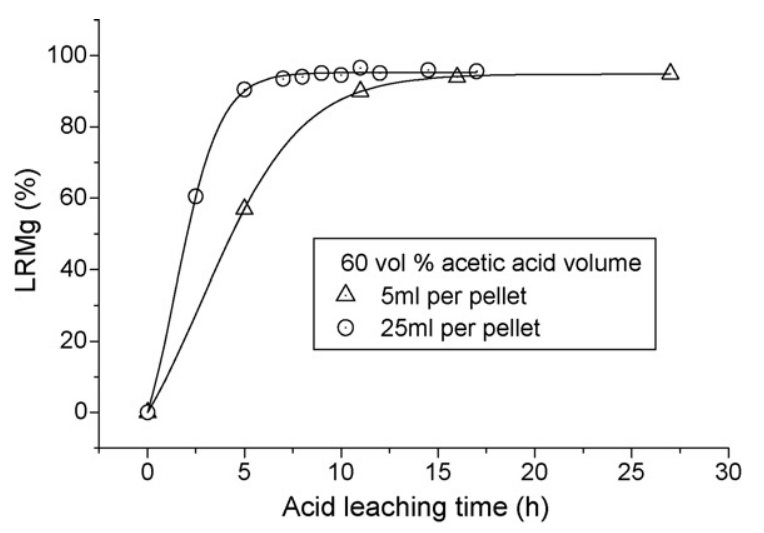

Fig. 4. Effect of acetic acid volume on the acid leaching efficiency of $\mathrm{CGM}_{3.3}(\mathrm{~S})$ pellet $(0.4 \mathrm{~g})$ in $60 \mathrm{vol} \%$ acetic acid solution of $25 \mathrm{ml}$ (circle) and $5 \mathrm{ml}$ (triangle) at $358 \mathrm{~K}$.

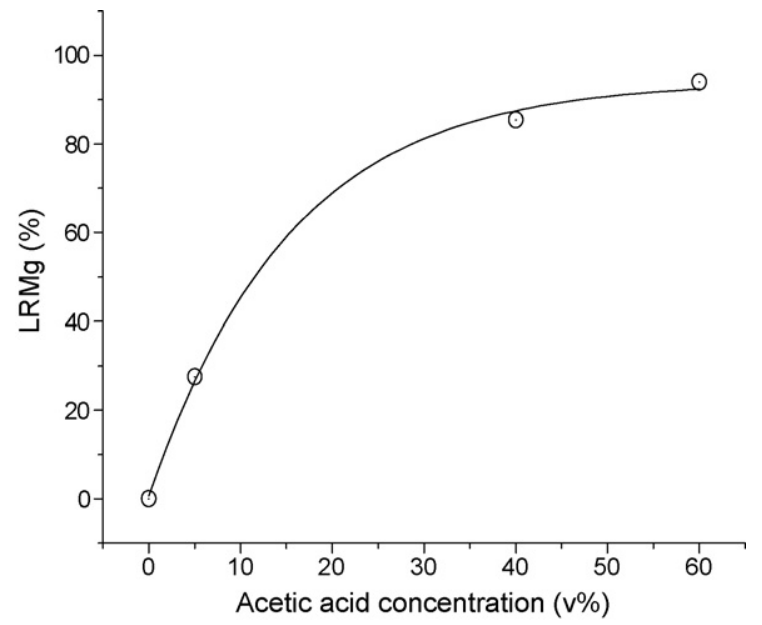

Fig. 5. Effect of acetic acid concentration on the LRMg at about $358 \mathrm{~K}$, for $8.5 \mathrm{~h}\left(\mathrm{CGM}_{3.3}(\mathrm{~S}): 0.4 \mathrm{~g}\right.$; acetic acid: $\left.25 \mathrm{ml}\right)$.

Fig. 3 shows the effect of acid leaching time on the shrinkage, the porosity, and the LRMg of the pellet. Although the shrinkage did not change apparently with time, both LRMg and porosity increased apparently with time and approached constants (about 96 and 68\%, respectively) after $8 \mathrm{~h}$. These results suggest that $\mathrm{MgO}$ in $\mathrm{CGM}(\mathrm{S})$ pellet can be effectively leached out, and that the acid leaching process cannot cause further shrink, but can cause great increase of porosity. Fig. 4 shows the effect of acetic acid volume on the acid leaching efficiency of the $\mathrm{CGM}_{3.3}(\mathrm{~S})$ pellet. The more the acetic acid solution, the shorter the sufficient leaching time is. If a $\mathrm{CGM}_{3.3}(\mathrm{~S})$ pellet $(0.4 \mathrm{~g})$ is leached with $25 \mathrm{ml}$ acetic acid solution $(60 \mathrm{vol} \%)$ at $358 \mathrm{~K}$, the sufficient leaching time is about 8 h. Fig. 5 shows the effect of acetic acid concentration on the LRMg of $\mathrm{CGM}_{3.3}(\mathrm{~S})$ pellet. With acid concentration increasing, the LRMg increased rapidly at first and then approached constant at the concentration of about $60 \mathrm{vol} \%$.

Fig. 6 shows the effect of the $\mathrm{MgO}$ content in $\mathrm{CGM}_{x}(\mathrm{~S})$ pellet on the porosity of the sufficiently leached pellet $\mathrm{CGM}_{x}(\mathrm{~L})$. The porosity increased with the increasing $\mathrm{MgO}$ content, and approached $68 \%$ at $x=3.3$. When $x>3.3$, the

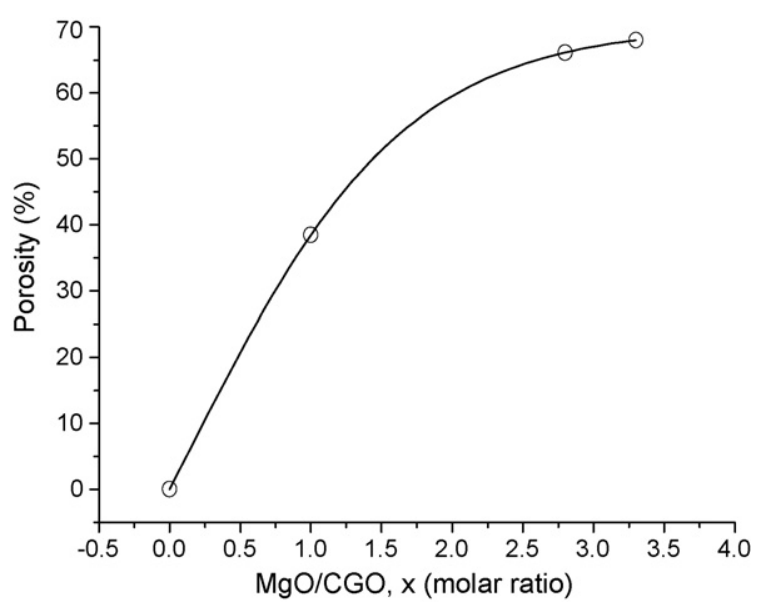

Fig. 6. Effect of $\mathrm{MgO}$ content $(x)$ in $\mathrm{CGM}_{x}(\mathrm{~S})$ on the porosity of sufficiently leached sample $\mathrm{CGM}_{x}(\mathrm{~L})$. Acid leaching conditions: $\mathrm{CGM}_{x}(\mathrm{~S})$ pellet $0.4 \mathrm{~g}$, $60 \mathrm{vol} \%$ acetic acid $25 \mathrm{ml}, 358 \mathrm{~K}, 21 \mathrm{~h}$. LRMg $\approx 97 \%$. 

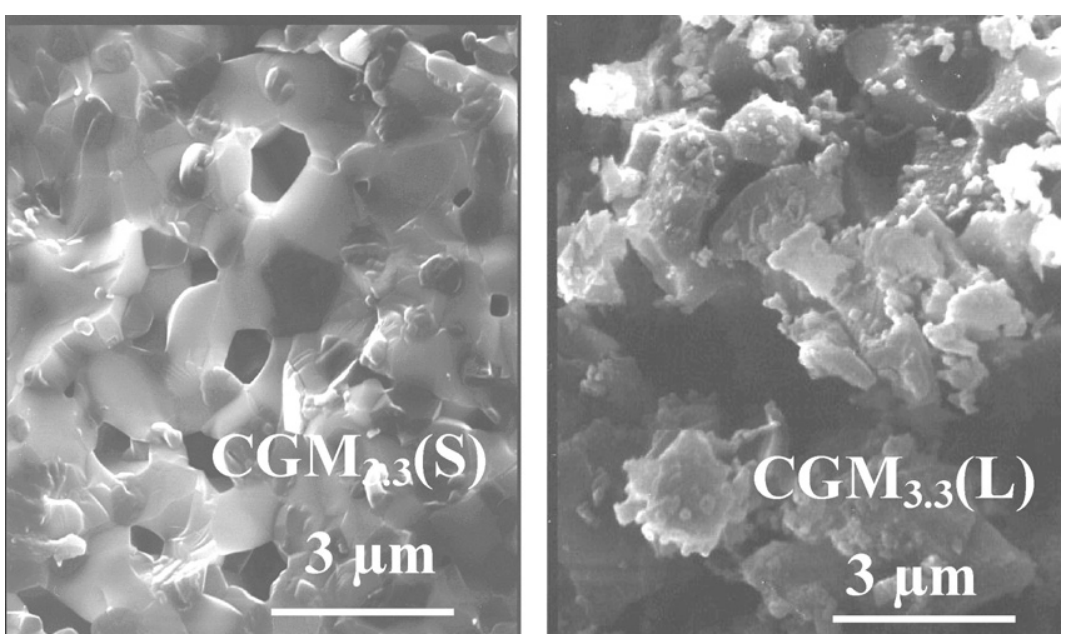

Fig. 7. SEM micrographs on the cross-sections of $\mathrm{CGM}_{3.3}(\mathrm{~S})$ and $\mathrm{CGM}_{3.3}(\mathrm{~L})$ pellets.

$\mathrm{CGM}_{x}(\mathrm{~L})$ pellet had a little higher porosity but much lower strength. The proper $x$ was found about 3.3.

Fig. 7 shows the SEM micrographs on the cross-sections of $\mathrm{CGM}_{3.3}(\mathrm{~S})$ and $\mathrm{CGM}_{3.3}(\mathrm{~L})$ pellets. Although smaller pores were still observed in $\mathrm{CSM}_{3.3}(\mathrm{~S})$ pellet, much more and larger pores were observed in the $\mathrm{CSM}_{3.3}(\mathrm{~L})$ pellet due to the removing of $\mathrm{MgO}$. These results are consistent not only with the porosity and LRMg results but also with the average pore size results [about $0.6 \mu \mathrm{m}$ for $\mathrm{CGM}_{3.3}(\mathrm{~S})$ and $1.7 \mu \mathrm{m}$ for $\left.\mathrm{CGM}_{3.3}(\mathrm{~L})\right]$. These large pores are beneficial to the preparation and function of the porous anode.

In literatures [2,3], porous CSO had been made with graphite as pore former, but its porosity could only achieve $50 \%$. This low porosity might be explained as follows. During the sintering process from room temperature to $1773 \mathrm{~K}$, the graphite started to burn at about $900 \mathrm{~K}$ and burnt out at about $1273 \mathrm{~K}$ [12], the pores thus produced might further shrink or even vanish during the rest sintering in higher temperature range (about 1273-1773 K), consequently, the porosity of the final product of porous $\mathrm{CSO}$ was low. In our present work, $\mathrm{MgO}$ was used as pore former. Since $\mathrm{MgO}$ could not burn during sintering, the pores produced by $\mathrm{MgO}$ through acid leaching at $358 \mathrm{~K}$ could be all reserved. Therefore, the porosity of the final porous CGO was quite high.

\section{Conclusions}

In summary, a new method was developed to prepare highly porous $\mathrm{CGO}$ by acid leaching $\mathrm{MgO}$ from $\mathrm{MgO}-\mathrm{CGO}$ ceramics with acetic acid solution. The effects of acid leaching conditions and $\mathrm{MgO}$ content were studied. Under proper leaching conditions (60 vol\% acetic acid, $358 \mathrm{~K}, 8.5 \mathrm{~h}$ ), $\mathrm{MgO}$ in $\mathrm{MgO}-\mathrm{CGO}$ ceramics can be effectively leached out but no CGO can be dissolved. The porosity of the sufficiently leached sample increases with the increasing $\mathrm{MgO}$ content, but too much $\mathrm{MgO}$ may result in the collapse of the leached samples.
The proper $\mathrm{MgO} / \mathrm{CGO}$ (molar ratio) is about 3.3. Under the proper conditions, highly porous CGO pellet can be made with a porosity of $68 \%$, much higher than that $(50 \%)$ with graphite as pore former.

\section{Acknowledgements}

The financial supports from the Ministry of Education and the National Science Council, Taiwan are gratefully acknowledged.

\section{References}

[1] N.Q. Minh, Ceramic fuel-cells, J. Am. Ceram. Soc. 76 (1993) 563-588.

[2] C. Lu, W.L. Worrell, R.J. Gorte, J.M. Vohs, SOFCs for direct oxidation of hydrocarbon fuels with samaria-doped ceria electrolyte, J. Electrochem. Soc. 150 (2003) A354-A358.

[3] C. Lu, W.L. Worrell, J.M. Vohs, R.J. Gorte, A comparison of Cu-ceriaSDC and Au-ceria-SDC composite for SOFC anodes, J. Electrochem. Soc. 150 (2003) A1357-A1359.

[4] A. Mortensen, S. Suresh, Functionally graded metals and metal-ceramics composites. Part I. Processing, Int. Mater. Rev. 40 (1995) 239-265.

[5] S.F. Corbin, P.S. Apte, Engineered porosity via tape casting, lamination and the percolation of pyrolyzable particulate, J. Am. Ceram. Soc. 82 (1999) 1693-1701.

[6] O. Lyckfeldi, J.M.F. Ferreira, Processing of porous ceramics by starch consolidation, J. Eur. Ceram. Soc. 18 (1998) 131-140.

[7] H. Kim, C. Rosa, M. Boaro, J.M. Vohs, R.J. Gorte, Fabrication of highly porous yttria stabilized zirconia by acid leaching nickel from a nickelyttria-stablized zirconia cermet, J. Am. Ceram. Soc. 85 (2002) 1473-1476.

[8] B.C.H. Steele, Solid State Ionics 129 (2000) 95.

[9] J. Van Herle, D. Seneviratne, A.J. McEvoy, J. Eur. Ceram. Soc. 19 (1999) 837.

[10] J. Van Herle, T. Horita, T. Kawada, N. Sakai, H. Yokokawa, M. Dokiya, Solid State Ionics 86-88 (1996) 1255.

[11] M. Mogensen, N.M. Sammes, G.A. Tompsett, Physical, chemical and electrochemical properties of pure and doped ceria, Solid State Ionics 129 (2000) 63-94.

[12] M. Boaro, J.M. Vohs, R.J. Gorte, Synthesis of highly porous yttria stabilized zirconia by tape casting methods, J. Am. Ceram. Soc. 86 (2003) 395-400. 